\title{
“TARIFF" A POWERFUL TOOL TO BRING AWARENESS IN EFFICIENT UTILIZATION OF ELECTRICAL ENERGY
}

\author{
Mohan Kumar $\mathbf{N}^{1}$, B. Kantharaj ${ }^{2}$, Poshitha $\mathbf{B}^{3}$, Manaswi K. $\mathbf{J}^{4}$ \\ ${ }^{1}$ M.Tech Scholar, Department of Power System Engineering, AIT, Chikkamagaluru /VTU, India \\ ${ }^{2}$ Associate Professor, Department of Electrical and Electronics Engineering, AIT, Chikkamagaluru /VTU, India \\ ${ }^{3}$ Assistant Professor, Department of Electrical and Electronics Engineering, AIT, Chikkamagaluru / VTU, India \\ ${ }^{4}$ Assistant Professor, Department of Electrical and Electronics Engineering, SJBIT Bengaluru /VTU, India
}

\begin{abstract}
Electrical Power/Energy is a mandatory aspect to lead our life and without this energy we can't imagine our life. In these days, there is a rapid development in power system; this is to improve system stability, reliability and quality of power (which is assured to the consumers).

The ultimate intension is to use this energy (with respect our requirements), efficient utilization always got a value. In this regard, Tariff plays a key role (in addition to the technologies in present power system). This paper presents some information about Tariff. Authorities (BESCOM) Tariff plans, which are applicable to the consumers in utilizing the energy. And a Reward/Penalty concept (Methodology) introduction to existing tariff (with an example).
\end{abstract}

$* * *$

\section{INTRODUCTION}

Tariff: It is the rate at which electrical energy is supplied to a consumer.

Electrical Power System is a complex network, includes Generation, Transmission \& Distribution of Electrical Power.

Further, the network is completed with the utilization of Electrical Power/Energy in many forms with respect to the application.

Domestic Application of Electrical Power/Energy is done in many ways, which are: Lighting, Heating, Refrigeration, Air Cooling, TV, Computers, Mobiles, Induction Owen, Washing Machine, Electric Iron, water lifting, etc.

Similarly, Industrial Application includes Compressors, Conveyors, Pumping, Rollers, Elevators, Heaters, Coolers, and Lighting etc.

Supplying Electrical Power/Energy to the consumers is done with a specified Tariff.

Includes,

Recovery of Cost of Generation \& Capital Investment at power Station.

Recovery of Cost on the Capital Investment in Transmission \& Distribution Systems.

Recovery of cost on the operation \& Maintenance of Electrical Power System.

Suitable Profit on Over All Investments.
Desirable Characteristics of a Tariff are:

Proper Return: Ensures proper return from each consumer. Fairness: Different Types of consumers are satisfied with respect to their usage.

Simplicity: The Tariff Shouldn't be Complicated, it should be easily understandable.

Reasonable Profit: This is for Electricity Supplying Company, for ensuring Quality of Power and Reliability.

Attractive: The Tariff should encourage the customer to use Electrical Power/Energy more and more.

Here one should know that, Tariff for the customers is different (Depending on the type of customers and demand). This is because Cost Generation at power plants will be different (Different for Hydro, Thermal, Nuclear, and Renewable Energy Sources). And maintaining System Stability is another major issue. Also depends on electricity supplying authority tie up's with power Transmission Authority, which further depends on Generation Authority.

Entire network is divided into Generation, Transmission and Distribution system. This is done to manage system complexity and to achieve proper control in system operation and maintenance.

Since the ultimate intension is to ensure reliability and quality of power. Tariff plays major role for both suppliers and customers. If the Tariff is attractive, then the customers are encouraged to use electrical energy more (increases per capita consumption). 
Similarly With the efficient operation of electrical power system, profit for all the authority will increase. Further contributes to the growth of our nation.

Efficient utilization of electrical energy is an important factor in improving system stability and its efficiency.

\section{TYPES OF TARIFF}

\subsection{Simple Tariff}

There is afixed rate per unit of energy consumed (also called uniform rate tariff).

\subsection{Flat Rate Tariff}

Different Types of consumers are charged at different uniform rates per unit consumption.

\subsection{Block Rate Tariff}

Unit rates are charged for the blocks of energy consumption (unit rate is progressively reduced For Consecutive blocks.ie; unit rate is from higher to lower).

\subsection{Two Part Tariff}

Unit rate is charged on the base of maximum demand and energy consumed over a period(Fixed and Running charges).

\subsection{Three Part Tariff}

Unit rate charged on the base of three parts. Fixed (includes interest, depreciation of DistributionNetwork and labour charges), Semi fixed (based on maximum demand) and running charges.

\subsection{Maximum Demand Tariff}

Unit rate is charged on the base of maximum demand (suitable for big consumers).

\subsection{Power Factor Tariff}

Unit rate is charged on base of power factor of energy consumed. Further the tariff is subdivided into 3 Types,

KVA Maximum Demand Tariff (KVA inversely proportional to PF concept).

Sliding Scale Tariff (PF Scale is set; consumer has to maintain the PF).

KW and KVAR Tariff (separate charges for real reactive power consumption).

[1]

BESCOM Authority consumer classification (LT Consumers).

LT-1: Applicable to installations serviced under Bhagyajyothi and Kutirajyothi (BJ/KJ) schemes.
LT-2(a)(i) : Applicable to areas coming under Bruhat Bangalore MahanagaraPalike (BBMP), Municipal Corporation and all Urban Local Bodies.

LT-2(a)(ii): Applicable to Areas under Village Panchayats.

LT-2(b)(i): Applicable to Areas under Bruhat Bangalore MahangaraPalike (BBMP) and Municipal Corporation and all areas coming under Urban LocalBodies.

LT-2(b)(ii): Applicable in Areas under Village Panchayats.

LT-3 (i): Applicable in areas coming under Bruhat Bangalore MahanagaraPalike (BBMP), Municipal Corporation and all areas under urban local bodies.

LT-3 (ii): Applicable in Areas under Village Panchayats.

LT-4 (a)Applicable to I.P. Sets Up to and inclusive of 10 HP.

LT-4 (b):Applicable to IP sets above $10 \mathrm{HP}$.

LT-4 (c) (i):Applicable to Private Horticultural Nurseries, Coffee, Tea and Rubber plantations of sanctioned load up to and inclusive of $10 \mathrm{HP}$.

LT-4 (c) (ii):Applicable to Private Horticultural Nurseries, Coffee, Tea and Rubber plantations of sanctioned load above $10 \mathrm{HP}$.

LT-5 (a): Applicable to Bruhat Bangalore MahanagaraPalike and Municipal Corporation.

LT-5 (b): Applicable to all Areas other than those covered under LT-5(a).

LT-6: Water Supply.

LT-7: Temporary Supply \& Advertising Hoardings. (Tariff details for different types of consumers are available in www.bescom.com).

Looking at LT-2(a)(i) consumer applicable to urban users, $[2,3]$

LT-2(a)(i) : Applicable to areas coming under Bruhat Bangalore MahanagaraPalike (BBMP), Municipal Corporation and all Urban Local Bodies. 


\begin{tabular}{|c|c|c|}
\hline \multirow[t]{2}{*}{$\begin{array}{l}\text { Fixed } \\
\text { charges } \\
\text { per } \\
\text { month }\end{array}$} & $\begin{array}{l}\text { For the } \\
\text { first KW }\end{array}$ & $\begin{array}{l}\text { Rs } 25 /- \text { per } \\
\text { KW }\end{array}$ \\
\hline & $\begin{array}{l}\text { For every } \\
\text { additional } \\
\mathrm{KW}\end{array}$ & $\begin{array}{l}\text { Rs } 35 /- \text { per } \\
\text { KW }\end{array}$ \\
\hline \multirow[t]{4}{*}{$\begin{array}{l}\text { Energy } \\
\text { charges }\end{array}$} & $\begin{array}{r}\text { For } 0-30 \\
\text { units (Lifeline } \\
\text { consumption) }\end{array}$ & $\begin{array}{l}270 \\
\text { Ps/unit }\end{array}$ \\
\hline & 31 to 100 units & 400 Ps /unit \\
\hline & 101 to 200 units & $525 \mathrm{Ps} /$ unit \\
\hline & Above 200 units & $625 \mathrm{Ps} /$ unit \\
\hline
\end{tabular}

The plan is operating with the combination of TWO Part and Block Rate Tariff. Here one difference is, Block Rate Tariff is operated in reverse mode, which is not entertaining the users consume more Electrical Energy.

To increase the Energy consumption and to achieve efficient utilization, there is a need to brought changes in existing Tariff plans (at least for urban users as initial step).

This can be achieved by the introduction of Reward / Penalty concept to the existing Tariff with slight modification in Block Rate Tariff (without violating the Tariff Constraints).

\section{REWARD / PENALTY CONCEPT TO}

\section{EXISTING TARIFF PLANS}

Concept implementation is explained below, In this concept, Consumer's average energy consumption (over the year) can be taken into account. And on the base of average energy consumption, a C-Link can be fixed to each consumer.

Example: If a user consumes 100 units/month (onthe base average energy consumption over the year), then C-Link to that user can be set as 95units/month (motto of C-Link concept introduction is to achieve efficient utilization of Electrical Energy).

Now with respect to the C-Link, if a user consumes energy, which is either less or more than the limits. Reward / Penalty on energy consumption can be made on the user.

To reduce complexity, Reward/Penalty introduction is made on the base of Percentage Energy consumption to the $\mathrm{C}$ Link. I.e., 5 units from C-Link insteps of 1 unit (which is either +/-). The amount to this concept is charged (in percentage) by taking gross total as reference.
Reward / Penalty amount runs as square of the units consumed to the total gross reference amount. The concept is true for first 3 units in both the zones, for the next two units (i.e. $4^{\text {th }}$ and $5^{\text {th }}$ ) this amount is $10 \%$ of gross total amount (bill amount).

If a user consumes 96 units/month, then there is 1 unit increase with respect to the C-Link. For this 1 unit, user is in Penalty zone. The amount charged to this 1 unit extra consumption is $1 \%$ of gross total which is added the new gross total.

On the other hand if user consumes 94 units/month, the user is in Reward Zone. For this 1 unit, $1 \%$ of gross total amount is deducted in the main bill. In doing so, naturally the user get attracted towards efficient utilization of electrical Energy.

This concept is helpful for both power supplying authorities and energy users. Further in future, if the user wants to consume more energy, which is beyond the C-Link. They can approach the concerned authority to change the C-Link which was previously assigned to them. Since the authority has the right to change the Tariff plans periodically with respect their constraints, they can decide the charges for extra energy demand to the same user.

This Reward/Penalty concept is restricted to 5 units from CLink. This is because Energy is there to utilize and utilize it when it is in need (Too much margin with respect to the CLink may become uneconomical for both Authority and users).

Here the previous Para example is giving info about only lunit (+/-) to the C-Link. Which is followed up to 5 units. For 2 units extra usage, Penalty of $4 \%$ of gross total amount is added to the new bill. Similarly if 2 units are less than CLink then $4 \%$ of gross total amount is deducted from the bill. This process is continued till up to 3 units in both the zones (Reward and Penalty). For $4^{\text {th }}$ and $5^{\text {th }}$ unit $10 \%$ amount is taken into account total bill (this is because $16 \%$ \& $25 \%$ amount may become uneconomical for authority and consumers).

Just to know the impact of this concept, if we had a look on the Number of consumers in BESCOM Karnataka State.

(As on 01/01/2015 (Including HT and LT Consumers)).

$\begin{array}{lr}\text { Domestic } & \mathbf{6 8}, \mathbf{0 5}, 124 \text { Nos. } \\ \text { Agriculture } & \mathbf{6 , 9 3 , 4 6 9} \text { Nos } \\ \text { Industries } & \mathbf{1 , 7 4 , 2 8 8} \text { Nos } \\ \text { Commercial } & \mathbf{8 , 2 9 , 6 5 9} \text { Nos } \\ \text { Others } & \underline{4,22,112} \text { Nos } \\ \text { Total } 89,24,652 . \text { Nos }\end{array}$

(Eighty Nine Lakh Twenty Four Thousand Six Fifty Two Nos).

Even if there is 1 unit saving is achieved by each consumer in a month, then $12,395(12.395 \mathrm{MWH})$ units available to 
supply power to other customers on hour basis. This energy can be tied up to new consumers or it can be used to maintain load shedding in urban and village areas (Reduces Power Outage Time, Improves Reliability and increases Revenue to the organization).

This is an example, which is given by considering only BESCOM Consumers. In Karnataka State, the other companies which are supplying electricity to the consumers are, MESCOM, HESCOM, CESCOM, GESCOM, and KPTCL. If this Reward / Penalty Concept is introduced in all the organizations and made clear to all the consumers of the state. Then definitely it is going to brought changes in efficient utilization of Electrical Energy. [2, 3]

Some of the points to be considered in efficient utilization of Electrical Energy (Domestic Loads) are,

$>\quad$ Use the energy when it is in need (it is precious).

$>$ Use energy efficient bulbs for illumination.

$>$ Set the refrigerator cooling point at min or at middle position and ensure that the door is always closed when not in use.

$>$ Use auto starters for motor application with level sensors in water lifting to overhead tanks.

$>\quad$ Do not let electric iron to get over heated in cloths ironing.

$>$ Operate washing machines in normal mode in washing the cloths.

$>$ Keep the windows open as much possible to have cooling and illumination in day time.

$>\quad$ While using AC's for cooling, keep the windows and doors closed.

$>$ Don't over charge mobiles in charging.

$>$ Ensure optimum utilization of UPS.

$>$ Use TV, Ceiling/Table Fans and other electronic equipment's optimally.

$>\quad$ Load the Grinders/Mixers optimally.

$>$ Use state and central govt schemes in encouraging distributed generation/micro grid generation using renewable energy.

$>$ Ensure domestic network to be fully protective against unpredictable faults, avoid repairing by unauthorised persons, Etc.[1,2,3 \&4]

\section{CONCLUSION}

Electrical Power/Energy is a precious asset in our life and we can't lead our life without this energy. Any countries Development/GDP is dependent on per capita power consumption of that country.

With the raise in power demand and short falls in meeting the demand, we are in need of efficient utilization of Electrical Energy. In achieving this, Tariff concept is helpful (for both consumers and power supply authorities).

If this Reward / Penalty concept is implemented in present Tariff plans (if required, modifications with respect to the charges can be done), then this is going help in power system financial perspectives, maintaining system stability, reliability and in assuring quality power to the consumers.
And also there is no doubt; it is going to bring awareness in efficient utilization of Electrical Energy.

\section{REFERENCES}

[1] V K Mehta - Principles of power system.

[2] Www.cerind.gov.in

[3] WWW.BESCOM.COM (Electricity Tariff 2015)

[4] Tariff Discussions with Technical People.

[5] Ramon Granell ${ }^{\mathrm{a}}$, , Colin J. Axon ${ }^{\mathrm{b}, 1,}$, David C.H. Wallom $^{\mathrm{a},}$-Predicting winning and losing Businesses when changing electricity tariffs.

[6] S. Darby - Load management at home: advantages and drawbacks of some 'active demand side' options.

[7] H. Sæle, O.S. Grande - Demand response from household customers: experiences from a pilot study in Norway.

[8] C.Saldarriaga, R.Hincapie, H. Salazar - A holistic approach for planning natural gas and electricity distribution networks.

[9] S. Borenstein - Wealth transfers among large customers from implementing real-time retail electricity pricing.

[10] P.Thorsnes, J. Williams, R. Lawson -Consumer responses to time varying prices for electricity. 